\title{
Ursolic acid inhibits breast cancer growth by inhibiting proliferation, inducing autophagy and apoptosis, and suppressing inflammatory responses via the PI3K/AKT and NF-кB signaling pathways in vitro
}

\author{
JUAN LUO ${ }^{1}$, YAN-LING HU ${ }^{1}$ and HONG WANG ${ }^{2}$ \\ Departments of ${ }^{1}$ Pharmacy and ${ }^{2}$ Surgical Oncology, Shaanxi Provincial People's Hospital, Xi'an, Shaanxi 710068, P.R. China
}

Received March 1, 2016; Accepted March 23, 2017

DOI: $10.3892 /$ etm.2017.4965

\begin{abstract}
Breast cancer, which is the second leading cause of cancer-associated mortality in women worldwide, develops from breast tissue. Chemotherapy is the most commonly used therapy to treat breast cancer. However, a number of natural plant-derived products have been suggested as alternative therapies to treat different types of cancer, such as breast cancer. The aim of the present study was to determine the anti-tumor effects of ursolic acid and its effect on apoptosis and inflammation in breast cancer cells. The anti-cancer effects of ursolic acid were evaluated in vitro using flow cytometry, western blotting and reverse transcription-quantitative polymerase chain reaction. The results suggest that ursolic acid inhibits the viability of breast cancer cells by inducing autophagy and apoptosis without inducing cell death. Cellular migration assays demonstrated that ursolic acid was able to suppress the invasive ability of breast cancer cells $(\mathrm{P}<0.05)$. In addition, the phosphoinositide 3-kinase (PI3K)/protein kinase B (AKT) pathway was downregulated following ursolic acid administration $(\mathrm{P}<0.05)$, leading to an upregulation of glycogen synthase kinase activity $(\mathrm{P}<0.05)$ and downregulation of B-cell lymphoma $2(\mathrm{P}<0.05)$, subsequently causing autophagy and apoptosis via cyclin-D1 inhibition and caspase-3 stimulation $(\mathrm{P}<0.05)$. Furthermore, the inflammatory response of breast cancer cells was assessed by measuring levels of nuclear factor $(\mathrm{NF})-\kappa \mathrm{B}$. Ursolic acid was found to downregulate $\mathrm{NF}-\kappa \mathrm{B}$ in breast cancer cells, thus inhibiting inflammation and preventing the progression of breast cancer $(\mathrm{P}<0.05)$. To the best of our knowledge, the present study is the first to assess the effect of ursolic acid on breast cancer cells through PI3K/AKT-regulated GSK and caspase-3 accompanied by
\end{abstract}

Correspondence to: Professor Juan Luo, Department of Pharmacy, Shaanxi Provinical People's Hospital, 256 Youyi Road, Xi'an, Shaanxi 710068, P.R. China

E-mail: luojuan710068@163.com

Key words: breast cancer, ursolic acid, autophagy, apoptosis, proliferation
$\mathrm{NF}-\kappa \mathrm{B}$ signaling pathways. The results of the present study regarding the potential underlying molecular mechanisms of ursolic acid may be used to develop novel therapeutic strategies for breast cancer treatment.

\section{Introduction}

It has been reported that breast cancer, which is the most common cancer in females across the world, accounts for $\sim 25 \%$ of all female malignancies and has a higher incidence in developed countries $(1,2)$. Furthermore, breast cancer is reportedly the second leading cause of cancer-associated mortality among females worldwide (3). Breast cancer is typically treated by surgical resection, which may be followed up by chemotherapy, radiation therapy or both (4). Treatments are constantly evaluated in randomized controlled trials to evaluate and compare the effectiveness of drugs used individually or in combination, as well as different surgical and radiation techniques (5). Investigations include novel forms of targeted therapy $(6,7)$. The aim of the present study was to identify novel reagents that have the potential to clinically treat breast cancer with low toxicity and minimal side effects.

The discovery of novel natural compounds with low toxicity the ability to inhibit cancer cells is an important area of cancer research (8). Ursolic acid (Fig. 1A) is a pentacyclic triterpenoid initially identified in the epicuticular waxes of apples in the $1920 \mathrm{~s}$ and is widely found in the peel of various fruits, as well as in herbs and spices including rosemary and thyme $(9,10)$. A number of potential biochemical effects of ursolic acid have been investigated, including antiproliferative, anti-inflammatory and anti-oxidant abilities (11); however, to date there have been no clinical studies demonstrating its benefits to human health. In vitro, ursolic acid inhibits the proliferation of various cancer cell types by inhibiting the signal transducer and activator of transcription 3 activation pathway, and may also decrease the proliferation of cancer cells and induce apoptosis (12). It has also been demonstrated that ursolic acid inhibits c-Jun N-terminal kinase expression and interleukin (IL)-2 activation, leading to a reduction in the proliferation and activation of T cells (13-15). At physiological concentrations, ursolic acid also induces eryptosis, which is the apoptosis-like suicidal cell death of defective red blood 
cells $(16,17)$. However, it remains unknown whether ursolic acid is able to target breast cancer cells by inhibiting tumor cell proliferation.

The phosphoinositide 3-kinase (PI3K)/protein kinase B (AKT) signaling pathway is an important part of intracellular signal transduction, cell proliferation, differentiation, apoptosis and migration, and is associated with metastasis and cancer progression in a variety of tumors $(18,19)$. Glycogen synthase kinase (GSK) is a protein downstream of AKT that is associated with the pathological progression of many types of cancer (20). The PI3K/AKT signaling pathway therefore acts by regulating cell growth and proliferation, at least partly via the modulation of GSK. Caspase activation and apoptosis, primarily regulated by the B-cell lymphoma 2 (Bcl-2) family that consists of pro- and anti-apoptotic members, serves a crucial role in tumor progression and growth $(21,22)$. The transcription factor nuclear factor (NF) $-\kappa \mathrm{B}$ serves a vital role in the inflammatory response, immunity, cell proliferation, differentiation and survival (23). Given that NF- $\kappa \mathrm{B}$ is considered to be a central link in the pathogenic processes of many tumors, it may represent a potential target for the treatment of breast cancer (24).

In the present study, it was hypothesized that ursolic acid may inhibit the proliferation of breast cancer cells in vitro, and may induce apoptosis and autophagy to suppress the development of breast cancer. It has been demonstrated that $\mathrm{NF}-\kappa \mathrm{B}$ is associated with inflammation that contributes to the development of breast cancer (25), which may be inhibited by ursolic acid. By inhibiting proliferation and inflammation, as well as inducing autophagy and apoptosis, ursolic acid may be developed as a novel method of treating breast cancer.

\section{Materials and methods}

Cell culture and treatment. The human breast cancer cell lines T47D, MCF-7 and MDA-MB-231 were obtained from the Shanghai Institute of Biochemistry and Cell Biology (Shanghai, China). T47D, MCF-7 and MDA-MB-231 cell lines were cultured for different time in each experiment as the following indicated in RPMI-1640 (Gibco, Thermo Fisher Scientific, Inc., Waltham, MA, USA) or Dulbecco's Modified Eagle's Medium (DMEM; Gibco; Thermo Fisher Scientific, Inc.) with $10 \%$ heat-inactivated fetal bovine serum (Invitrogen; Thermo Fisher Scientific, Inc.) and $1 \%$ penicillin/streptomycin at $37^{\circ} \mathrm{C}$ in an atmosphere containing $5 \% \mathrm{CO}_{2}$. Ursolic acid was purchased from Shanghai Yuanye Biological Technology Co., Ltd. (Shanghai, China) and was dissolved in dimethyl sulfoxide (DMSO) at various concentrations (0, 10, 20, 40, 80, 160 , and $320 \mathrm{ug} / \mathrm{ml}$ ) prior to cell administration.

Cell viability assays. The effects on cell viability of ursolic acid administration were determined by Sulforhodamine B (SRB) assay or assessed by manual counting with a standard hemocytometer followed by trypan blue staining. T47D, MCF-7 and MDA-MB-231 cells were seeded in a 96-well plate a density of 3,000 cells/well, allowed to adhere overnight, and treated with different doses of ursolic acid $(0,10,20,40,80,160$, and $320 \mathrm{ug} / \mathrm{ml}$ ) for 3 days at $37^{\circ} \mathrm{C}$. Cells were subsequently fixed with $10 \%$ trichloroacetic acid for $1 \mathrm{~h}$ at $4^{\circ} \mathrm{C}$, washed with deionized water and stained with $0.4 \%$ SRB dye (Sigma-Aldrich; Merck KGaA, Darmstadt, Germany) for $15 \mathrm{~min}$ at room temperature. Cells were then washed with acetic acid and the SRB dye was dissolved with unbuffered Tris at a concentration of $10 \mathrm{mmol} / 1$. Optical density was determined at $540 \mathrm{~nm}$ using a plate reader. To create growth curves, breast cancer cells from each cell line were treated with ursolic acid for indicated time $(0,1,2,3,4,5$, and 6 days), and the cell growth was measured after each treatment. The total number of cells was assessed following trypan blue staining at room temperature using a scanning microscope (magnification, x20; FV1200, Olympus Corp, Japan) and at least 5 areas were randomly selected and analyzed by CellProfiler software (Version 2.1.0; Broad Institute, Cambridge, MA, USA).

Measurement of apoptosis. Cell apoptosis was determined by flow cytometry (Cytomics FC 500 MCL; Beckman Coulter, Inc., Brea, CA, USA). Determination of apoptosis in T47D, MCF-7 and MDA-MB-231 cells was performed using Annexin V-FITC and propidium iodide double staining kits following the manufacturer's protocol (eBioscience; Thermo Fisher Scientific, Inc.). Briefly, 2x10 $547 D$, MCF-7 and MDA-MB-231 cells were pretreated with nicotine and hyperoside for $48 \mathrm{~h}$ at $37^{\circ} \mathrm{C}$. The cells were subsequently harvested using trypsin (Gibco; Thermo Fisher Scientific, Inc.) and suspended in DMEM. Cell suspensions were centrifuged at $800 \mathrm{x} \mathrm{g}$ for $5 \mathrm{~min}$ to remove cellular debris and impurities at $4^{\circ} \mathrm{C}$. All cells were washed twice in Hank's buffer (Gibco; Thermo Fisher Scientific, Inc.). Cells were subsequently double-stained with Annexin V-FITC and propidium iodide for $30 \mathrm{~min}$ at room temperature.

Colony-forming assay. T47D, MCF-7 and MDA-MB-231 cells were seeded at a density of 1,000 cells/well in a 6-well plate, allowed to adhere overnight and administered with the indicated dosages $(0,160$, and $320 \mu \mathrm{g} / \mathrm{ml})$ of ursolic acid. Following 6 days culture at $37^{\circ} \mathrm{C}$, the cells were fixed with methanol, stained with crystal violet and the numbers of colonies with $>50$ cells were counted in 5 random fields using a scanning microscope (magnification, x20; Olympus FV1200).

Cell migration assay. The cell migration assay was performed using 24-well Transwell chambers, and untreated cells were used as the control group. A total of $1 \times 10^{5}$ T47D, MCF-7 and MDA-MB-231 cells were seeded in the top chamber of Transwell plates. A total of $600 \mathrm{ml}$ ursolic acid was added to the lower chambers in DMEM. Chambers were incubated for $24 \mathrm{~h}$ at $37^{\circ} \mathrm{C}$. PBS was used to wash the upper sides of the membrane and the remaining cells were removed. Transwell membranes were fixed and stained with $0.1 \%$ crystal violet for $5 \mathrm{~min}$ at room temperature and migrated cells were counted via light microscopy. The mean number of cells migrated in each field was examined by counting $\geq 4$ random fields per filter. Each experiment was repeated three times.

Wound healing assay. Human breast cancer cells $\left(1 \times 10^{5}\right)$ were cultured in 24-well plates and placed into an incubator at $37^{\circ} \mathrm{C}$ until they reached $90 \%$ confluence. Cell migration was measured using a wound healing assay. In brief, scratch wounds of the same width on each cell monolayer were created with a sterile $10 \mu \mathrm{l}$ pipette tip. The detached cells were removed by washing with PBS. Cells were subsequently treated with 
Table I. Primer sequences used for reverse transcription-quantitative polymerase chain reaction.

\begin{tabular}{lll}
\hline Gene & \multicolumn{1}{c}{ Forward primers $\left(5^{\prime}-3^{\prime}\right)$} & Reverse primers $\left(5^{\prime}-3^{\prime}\right)$ \\
\hline LC-3 & GTCGTTGCAGACTATTCAGAG & GTATCCGACAGAGTACAGCAT \\
Caspase-3 & GGAGGACAACACTTCGAATTA & CACAGGTATGCACGACTAAAT \\
TNF- $\alpha$ & CAGACCGGACGCTACACC & GAACACGTCTTGTCCGACCA \\
IL-6 & AGAGCACGACATGTAGGCA & ACGTCCAGTTATTGGGTG \\
IL-18 & AGCAGAAGTCAGCCAGGTA & TCGGCGCAAGTGTTATTGGGT \\
IFN- $\gamma$ & AGGCGGAACGTGGTGTGGCA & TGATCCGCCTTGGTCGTGTTCC \\
GAPDH & CACAATTGGGACCACAAGGG & AACTCATCACAGCACGTCACACC
\end{tabular}

LC-3, LC3, microtubule-associated protein 1A/1B-light chain 3; TNF, tumor necrosis factor; IL, interleukin; IFN, interferon.

ursolic acid $(0,160$, and $320 \mu \mathrm{g} / \mathrm{ml})$ to block cellular migration. Images were captured at $48 \mathrm{~h}$, and the distance traveled by the cells indicated the closure of the wounds.

Western blot analysis. Cell proteins were extracted using a T-PER Tissue Protein Extraction Reagent kit (Thermo Fisher Scientific, Inc.) according to the manufacturer's protocol. Protein concentrations were determined using a bicinchoninic acid protein assay kit (Thermo Fisher Scientific, Inc.) and $40 \mu \mathrm{g}$ equal protein was loaded per lane and separated by $10 \%$ SDS-PAGE. Proteins were subsequently transferred onto polyvinylidene difluoride membranes. Membranes were blocked with Tris-buffered saline containing 0.05\% Tween-20 (TBS-T), supplemented with 5\% skim milk (Sigma-Aldrich; Merck $\mathrm{KGaA}$ ) at room temperature for $2 \mathrm{~h}$ on a rotary shaker, followed by TBS-T washing 5 times for $5 \mathrm{~min}$. The membranes were incubated at $4^{\circ} \mathrm{C}$ overnight with the primary antibodies against the following (diluted in TBST): PI3K (1:1,000; ab86714; Abcam, Cambridge, UK), phosphorylated (p)-AKT (1:1,000; ab38449; Abcam), AKT (1:1,000; ab8805; Abcam), p-GSK3 $\beta$ (1:1,000; ab75745; Abcam), GSK3 $\beta$ (1:1,000; ab32391; Abcam), cyclin-D1 (1:1,000; ab16663; Abcam), Bcl-2 (1:1,000; ab59348; Abcam), Bcl-xL (1:1,000, ab32370; Abcam), Bcl-2-associated death promoter (Bad) (1:1,000; ab32445; Abcam), Bcl-2-like protein 4 (Bax; 1:1,000; ab32503; Abcam), caspase-9 (1:1,000; ab52298; Abcam), caspase-3 (1:1,000; ab13847; Abcam), inhibitor of $\kappa \mathrm{B}(\mathrm{I} \kappa \mathrm{B}) \alpha(1: 1,000$; ab32518; Abcam), I $\mathrm{B}$ kinase (IKK) $\alpha(1: 1,000 ;$ ab178870; Abcam), nuclear factor (NF)-кB (1:1,000; ab16502; Abcam), p-NF-кB (1:1,000; ab86299; Abcam), IL-1 $\beta$ (1:1,000; 12242; Cell Signaling Technology, Inc., Danvers, MA, USA), IL-18 (1:1,000; ab191152; Abcam) and GAPDH (1:2,00, sc-32233; Santa Cruz Biotechnology, Inc., Dallas, TX, USA). The membrane was subsequently washed with TBST and incubated with the peroxidase-conjugated secondary antibody (bovine anti-rabbit IgG-HRP; 1:5,000; sc-2370; Santa Cruz Biotechnology, Inc.) at room temperature for $1 \mathrm{~h}$. The immunoactive proteins were detected by using an enhanced chemiluminescence western blotting detection kit (Thermo Fisher Scientific, Inc.) according to the manufacturer's protocol. Western blot bands were assessed using the ECL Western Blotting Analysis System (GE Healthcare Life Sciences, Chalfont, UK) and exposed to x-ray film. Protein expression levels were defined as grey value (ImageJ version 1.4.2b; National Institutes of Health, Bethesda, MD, USA) and standardized to housekeeping genes (GAPDH). All the results are from at least three independent experiments.

Reverse transcription-quantitative polymerase chain reaction $(R T-q P C R)$. Breast cancer cells were treated with ursolic acid $(0,160$, and $320 \mathrm{ug} / \mathrm{ml})$ for $48 \mathrm{~h}$ and harvested. Total RNA was isolated from breast cancer cells with TRIzol ${ }^{\circledR}$ reagent (Invitrogen; Thermo Fisher Scientific, Inc.) following the manufacturer's protocol. A total of $1 \mu \mathrm{g}$ RNA was reverse transcribed into cDNA using the SuperScript First-Strand Synthesis kit (Invitrogen; Thermo Fisher Scientific, Inc.). The reaction was carried out at $42^{\circ} \mathrm{C}$ for $1 \mathrm{~h}$ and terminated by deactivation of the enzyme at $70^{\circ} \mathrm{C}$ for $10 \mathrm{~min}$. The primers used are listed in Table I. All primer sequences were checked in GeneBank (https://www.ncbi.nlm.nih.gov/genbank) to avoid inadvertent sequence homologies and primers were designed and synthesized by BioGenes GmbH (Berlin, Germany). Reactions were performed using the SYBR-Green PCR master mix (Applied Biosystems; Thermo Fisher Scientific, Inc.) on a Bio-Rad iCycler iQ Detection system (Bio-Rad Laboratories, Inc., Hercules, CA, USA). The sample cDNA was amplified in 96-well optical reaction plates (Invitrogen; Thermo Fisher Scientific, Inc.) containing $2 \mu \mathrm{l}$ of cDNA, $10 \mu \mathrm{l}$ of iTaq Universal SYBR-Green Supermix (Bio-Rad Laboratories, Inc.), $1 \mu \mathrm{l}$ of primers (forward and reverse). Amplification of pre-denatured products was conducted at $94^{\circ} \mathrm{C}$ for $60 \mathrm{sec}$; followed by 45 cycles at $95^{\circ} \mathrm{C}$ for $30 \mathrm{sec}, 58^{\circ} \mathrm{C}$ for $30 \mathrm{sec}$ and $72^{\circ} \mathrm{C}$ for $30 \mathrm{sec}$; followed by $95^{\circ} \mathrm{C}$ for $10 \mathrm{sec}, 65^{\circ} \mathrm{C}$ for $45 \mathrm{sec}$, and $40^{\circ} \mathrm{C}$ for $60 \mathrm{sec}$. GAPDH levels were quantified in parallel with target genes as an internal control. Normalization and fold change for each of the genes were calculated using the $2^{-\Delta \Delta \mathrm{Cq}}$ method (26).

Statistical analysis. Data are expressed as the mean \pm standard error of the mean. Treated cells, tissues and the corresponding controls were compared using GraphPad PRISM software (version 6.0; GraphPad Software, Inc., La Jolla, CA, USA). One-way analysis of variance followed by Dunn's least significant difference tests was used to analyze data. $\mathrm{P}<0.05$ was considered to indicate a statistically significant difference.

\section{Results}

Ursolic acid suppresses breast cancer cell viability. To investigate the optimal ursolic acid concentration to suppress the 
A

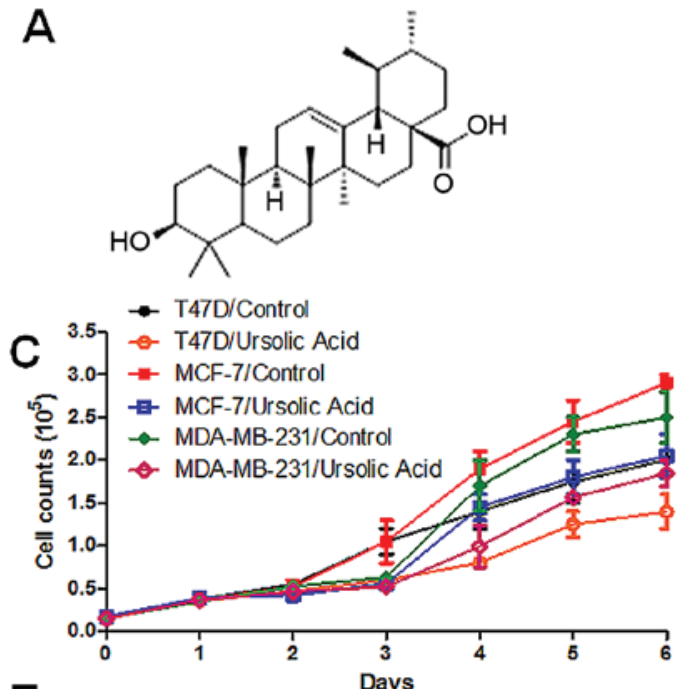

E

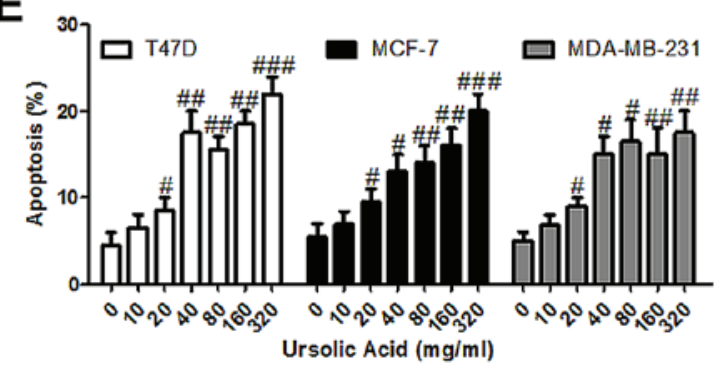

B

\begin{tabular}{cc}
\multicolumn{2}{c}{$\mathbf{I C}_{50}$ values of Ursolic Acid } \\
\hline Cell lines & $\mathrm{IC}_{50}(\mu \mathrm{g} / \mathrm{ml})$ \\
\hline T47D & $231.56 \pm 10.3$ \\
MCF-7 & $221.39 \pm 9.4$ \\
MDA-MB-231 & $239.47 \pm 15.88$ \\
\hline
\end{tabular}

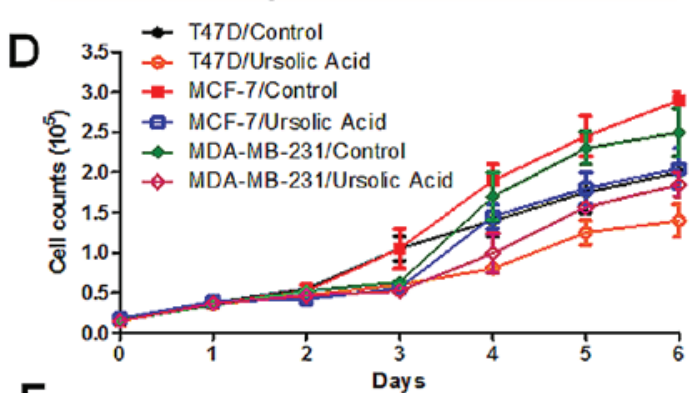

F

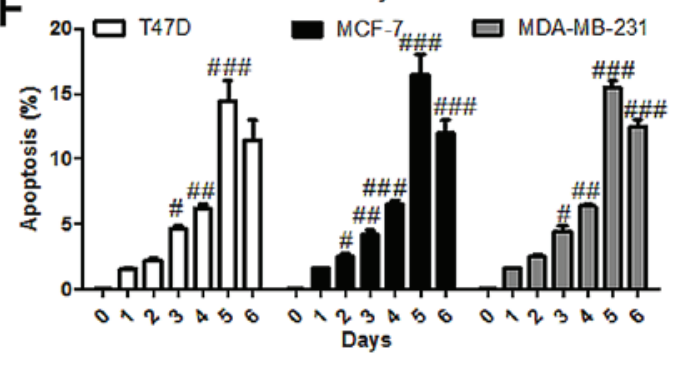

Figure 1. Effect of ursolic acid on the viability and apoptosis of breast cancer cells. (A) The chemical structure of ursolic acid. (B) SRB assays were used to determine the $\mathrm{IC}_{50}$ following the administration of different concentrations of ursolic acid for 3 days. (C) SRB assays were performed to determine the viability of breast cancer cells following the administration of different concentrations of ursolic acid for 3 days. (D) The viability of breast cancer cells was examined via SRB assay following treatment with $160 \mu \mathrm{g} / \mathrm{ml}$ ursolic acid for 6 days. (E) Flow cytometry was performed to determine the apoptosis of breast cancer cells following the administration of different concentrations of ursolic acid for 3 days. (F) Flow cytometry was performed to determine the apoptosis of breast cancer cells following treatment with $160 \mu \mathrm{g} / \mathrm{ml}$ ursolic acid for different amounts of times. Data are expressed as the mean \pm standard error of the mean. ${ }^{\#} \mathrm{P}<0.05,{ }^{\# \#} \mathrm{P}<0.01$ and ${ }^{\# \# \#} \mathrm{P}<0.001$ vs. control group. SRB, Sulforhodamine B; $\mathrm{IC}_{50}$, half maximal inhibitory concentration.

viability of human breast cancer cells, different concentrations $(0,50,100,150,200,250$, and $300 \mathrm{ug} / \mathrm{ml})$ of ursolic acid were examined in T47D, MCF-7 and MDA-MB-231 cell lines with SRB assays. It was observed that $0-300 \mu \mathrm{g} / \mathrm{ml}$ ursolic acid markedly suppressed breast cancer cell viability in all cell lines in a dose-dependent manner (Fig. $1 \mathrm{~B}$ and $\mathrm{C}$ ). The $\mathrm{IC}_{50}$ values were 231, 221 and $239 \mu \mathrm{g} / \mathrm{ml}$ in T47D, MCF-7 and MDA-MB-231 cell lines respectively. A dosage of $160 \mu \mathrm{g} / \mathrm{ml}$ ursolic acid was found to markedly reduce cell viability in a time-dependent manner compared with the control group for all cell lines (Fig. 1D). Based on these results, all subsequent experiments were performed using $160 \mu \mathrm{g} / \mathrm{ml}$ ursolic acid. Furthermore, a significant increase in apoptosis was observed following treatment with ursolic acid $(\mathrm{P}<0.05)$. This increase was observed in all cell lines and occurred in a dose- and time- dependent manner (Fig. 1E and F). These results suggest that ursolic acid is able to significantly inhibit the viability of breast cancer cells.

Ursolic acid inhibits the migration of breast cancer cell lines. Colony formation was used to assess the migration and proliferation of breast cancer cells. It was observed that the number of colonies significantly decreased following treatment with $\geq 160 \mu \mathrm{g} / \mathrm{ml}$ ursolic acid in the T47D $(\mathrm{P}<0.05)$, MCF-7 $(\mathrm{P}<0.01)$ and MDA-MB-231 $(\mathrm{P}<0.05)$ cell lines (Fig. 2A). Furthermore, cell migration assays were conducted, the results of which demonstrated that treatment with $\geq 160 \mu \mathrm{g} / \mathrm{ml}$ ursolic acid significantly inhibited cell invasion in a dose-dependent manner in the T47D $(\mathrm{P}<0.05), \mathrm{MCF}-7$ $(\mathrm{P}<0.01)$ and MDA-MB-231 $(\mathrm{P}<0.01)$ cell lines (Fig. 2B). In addition, a wound healing assay was used to analyze the migration of cells. The results demonstrated that the wound area was significantly reduced in the T47D $(\mathrm{P}<0.01)$, MCF-7 $(\mathrm{P}<0.01)$ and MDA-MB-231 $(\mathrm{P}<0.001)$ cell lines treated with $320 \mu \mathrm{g} / \mathrm{ml}$ ursolic acid compared with the control (Fig. 2C). These data suggest that ursolic acid may serve a potential role in attenuating breast cancer progression by suppressing cell migration, invasion and proliferation in vitro.

Ursolic acid inhibits proliferation and induces apoptosis and autophagy via the PI3K/AKT signaling pathway. Previous studies have suggested that autophagy and apoptosis are important in inhibiting tumor growth $(27,28)$ and it has been reported that PI3K/AKT serves an essential role in proliferation via the AKT-regulated GSK signaling pathway (20). In the present study, it was demonstrated that following treatment with ursolic acid, the expression of PI3K was markedly downregulated in all of the three cell lines and the phosphorylation of AKT was markedly inactivated (Fig. 3A). GSK activation markedly increased with the decrease in AKT activation, which led in turn to a marked downregulation in cyclin-D1 expression (Fig. 3A). This downregulation in cyclin-D1 may 
A

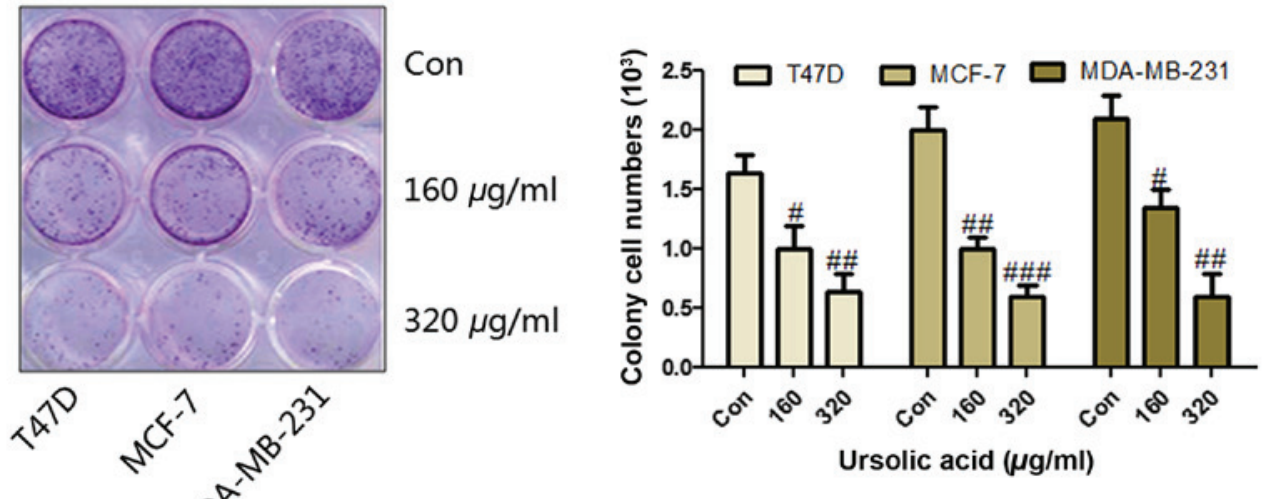

B

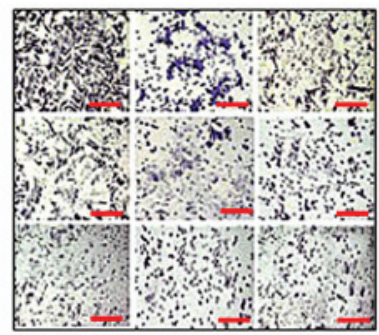

Con

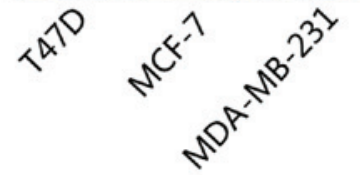

$160 \mu \mathrm{g} / \mathrm{ml}$

$320 \mu \mathrm{g} / \mathrm{ml}$

C

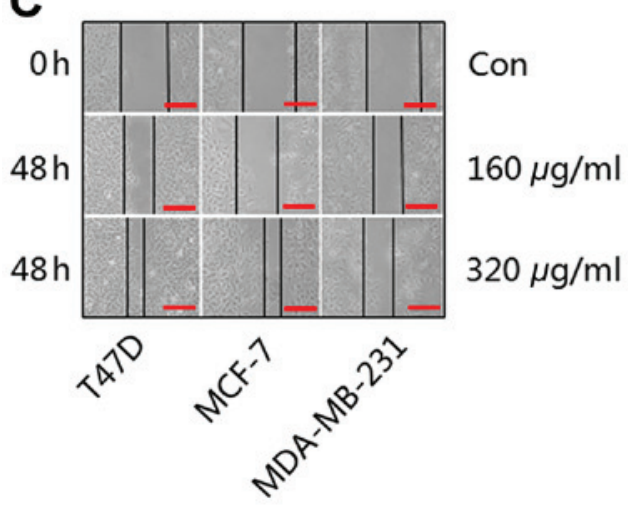

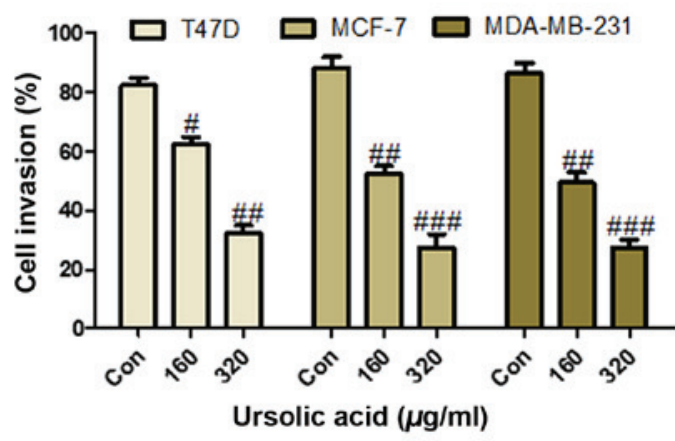

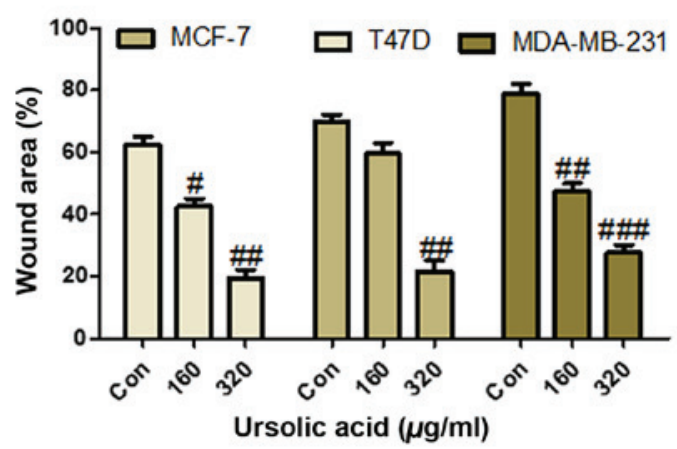

Figure 2. Ursolic acid inhibits the migration of breast cancer cell lines. (A) Colony formation of breast cancer cells was assessed following the administration of different concentrations of ursolic acid for 6 days. (B) Cells were seeded on the Transwell plates and treated with $160 \mathrm{or} 320 \mu \mathrm{g} / \mathrm{ml} \mathrm{ursolic}$ acid and migrated cells were stained and counted using light microscopy (magnification, $\mathrm{x} 40$ ). (C) Wound healing assays were performed to analyze cell migration following $48 \mathrm{~h}$ treatment with ursolic acid. Data are expressed as the mean \pm standard error of the mean. ${ }^{\#} \mathrm{P}<0.05,{ }^{\# \#} \mathrm{P}<0.01$ and ${ }^{\# \# \#} \mathrm{P}<0.001 \mathrm{vs}$. control group. Con, control.

promote cell proliferation due to the activation of PI3K/AKT. Furthermore, microtubule-associated protein 1A/1B-light chain 3 (LC3) is a marker for autophagy. Levels of LC3 mRNA were significantly upregulated in T47D, MCF-7 and MDA-MB-231 cells treated with ursolic acid ( $\mathrm{P}<0.01$; Fig. $3 \mathrm{~B})$, suggesting that autophagy occurred in a dose-dependent manner. The expression of apoptotic proteins was measured by western blotting. It was determined that levels of Bcl-2, an important anti-apoptotic factor and Bcl-xL, which belongs to the Bcl-2 family, were markedly decreased following the administration of ursolic acid in all cell lines (Fig. 3C). Bad and Bax are pro-apoptotic factors that are able to induce apoptosis formation via caspase-3 activation. In the present study, levels of Bad and Bax were found to be markedly upregulated following ursolic acid stimulation (Fig. 3C). Caspase-9 and caspase-3 were also significantly activated following ursolic acid treatment (Fig. 3C). Levels of caspase-3 mRNA were further assessed to confirm whether ursolic acid was able to induce apoptosis and inhibit breast cancer development. Levels of caspase-3 mRNA were found to be significantly upregulated in all breast cancer cell lines treated with 160 or $320 \mu \mathrm{g} / \mathrm{ml}$ ursolic acid $(\mathrm{P}<0.01$ and $\mathrm{P}<0.001$, respectively; Fig. 3D) compared with the control cells. These results suggest that ursolic acid is able to suppress breast cancer growth via induction of autophagy and apoptosis in vitro.

Ursolic acid suppresses the inflammatory response via the $I K K \alpha / N F-\kappa B$ signaling pathway. Inflammation is known 
A

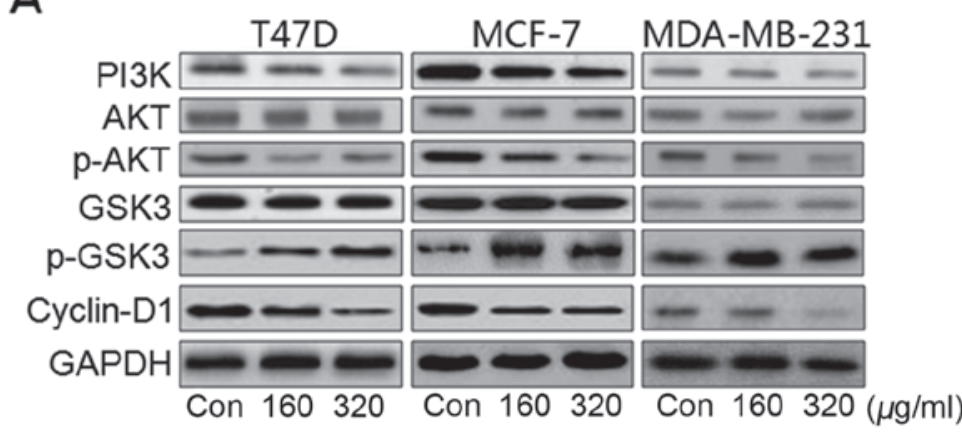

C

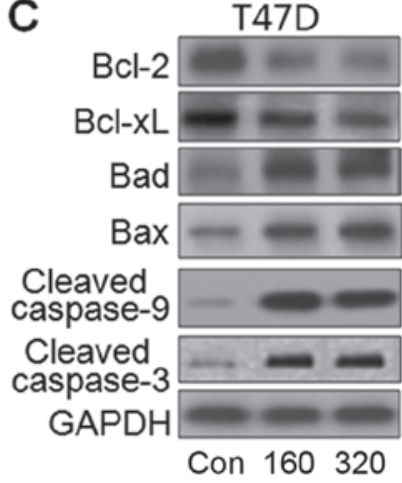

MCF-7

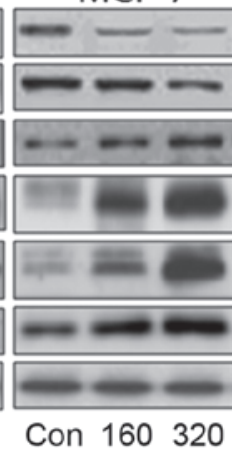

MDA-MB-231

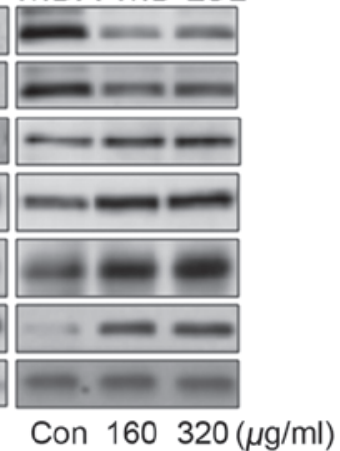

B

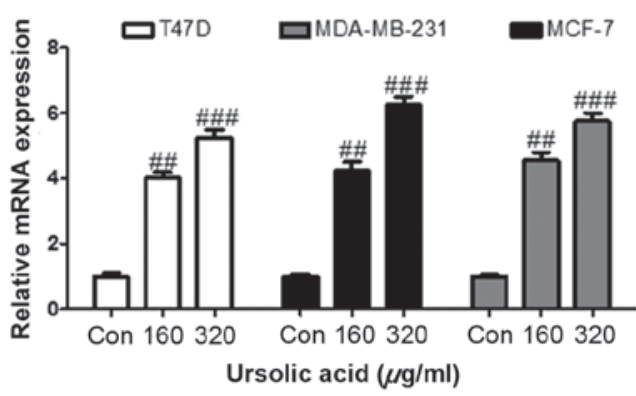

D

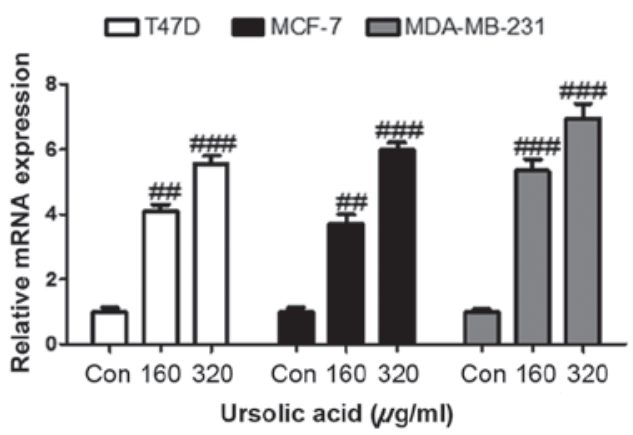

Figure 3. Ursolic acid inhibits proliferation and induces apoptosis and autophagy via the PI3K/AKT signaling pathway. (A) Western blot assays were used to assess the levels of PI3K, p-AKT, p-GSK3 $\beta$ and cyclin-D1 expression in three different breast cancer cell lines. (B) RT-qPCR assays were used to determine LC3 levels in breast cancer cells following treatment with 160 or $320 \mu \mathrm{g} / \mathrm{ml}$ ursolic acid. (C) Western blot assays were used to assess levels of Bcl-2, Bcl-xL, Bad, Bax, caspase-9 and caspase-3 following ursolic acid administration; (D) Levels of caspase-3 mRNA in breast cancer cells was assessed via RT-qPCR. Data are expressed as the mean \pm standard error of the mean. ${ }^{\# \#} \mathrm{P}<0.01$ and ${ }^{\# \# \#} \mathrm{P}<0.001$ vs. control group. PI3K, phosphoinositide 3 -kinase; AKT, protein kinase $\mathrm{B}$; $\mathrm{p}$, phosphorylated; GSK glycogen synthase kinase; RT-qPCR, reverse transcription-quantitative polymerase chain reaction; LC3, microtubule-associated protein 1A/1B-light chain 3; Bcl, b-cell lymphoma; Bad, Bcl-2-associated death promoter; Bax, Bcl-2-like protein 4; Con, control.

to serve a vital role in tumor formation and $N F-\kappa B$ has been reported to be crucial for the inflammatory response in cancer (29). In the present study, the NF- $\kappa \mathrm{B}$ signaling pathway was investigated to indicate whether ursolic acid was able to suppress breast cancer progression via inhibition of inflammation. It was observed that IKK $\alpha$ was markedly inactivated following administration of 160 or $320 \mu \mathrm{g} / \mathrm{ml}$ ursolic acid (Fig. 4A). Due to the downregulation of IKK $\alpha$, $\mathrm{I} \kappa \mathrm{B} \alpha$ was also markedly decreased following ursolic acid treatment and levels of phosphorylated NF- $\mathrm{B}$ were markedly decreased in all cell lines (Fig. 4A). Furthermore, levels of pro-inflammatory cytokines including IL-1 $\beta$ and IL-18, were markedly downregulated following ursolic acid administration, compared with the control. RT-qPCR was performed to assess mRNA levels of other pro-inflammatory cytokines and growth factors in breast cancer cells. Levels of TNF- $\alpha$ were significantly reduced following treatment with 160 or $320 \mu \mathrm{g} / \mathrm{ml}$ ursolic acid in the T47D ( $<<0.001$; Fig. 4B), MCF-7 $(\mathrm{P}<0.05$; Fig. 4C) and MDA-MB-231 ( $\mathrm{P}<0.05$; Fig. 4D) cells. Levels of Il- 6 were significantly downregulated in all cell lines following the administration of 160 or $320 \mu \mathrm{g} / \mathrm{ml}$ ursolic acid (all $\mathrm{P}<0.01$; Fig. 4B-D). Treatment with ursolic acid induced a significant downregulation in both IL-18 and interferon (IFN) $-\gamma$ expression in the T47D $(\mathrm{P}<0.01$ and $\mathrm{P}<0.05$, respectively; Fig. 4B), MCF-7 (both $\mathrm{P}<0.05$; Fig. 4C) and MDA-MB-231 (both $\mathrm{P}<0.05$; Fig. 4D) cells. This downregulation occurred in a dose-dependent manner (Fig. 4). These results suggest that ursolic acid may ameliorate breast cancer progression by suppressing the inflammatory response.

\section{Discussion}

Breast cancer is a highly prevalent disease worldwide and develops via a complex multistep process (1). There are three phases to this process: Initiation, progression and metastasis composed of a sequence of events involving self-renewal apoptosis, cell cycle and mobility (30). Ursolic acid is a triterpene compound derived from the fruits, berries, leaves and flowers of medicinal plants (31). It has been used in throughout Asia as an anti-tumor, anti-inflammatory, anti-hyperglycemia and immunomodulatory agent $(13,14)$. However, the underlying molecular mechanisms responsible for its beneficial effects remain unclear, including the mechanism by which it inhibits breast cancer progression and growth in humans.

Previous studies have suggested that ursolic acid may inhibit the formation and progression of many types of cancer, including colorectal, bladder and ovarian cancer, via suppression of proliferation $(32,33)$. In the present study, it was suggested that ursolic acid is able to inhibit breast cancer cell migration, invasion and proliferation, indicating that it may have potential applications for clinical treatments in the future. Furthermore, the results of the present study implicated the PI3K signaling pathway in cell survival and apoptosis. Akt is a major effector in the PI3K signaling pathway and an 
A

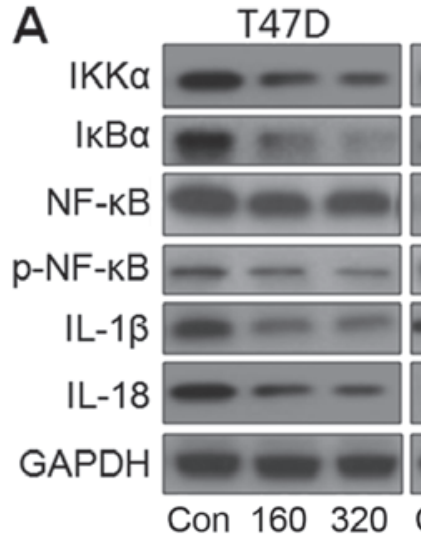

MCF-7

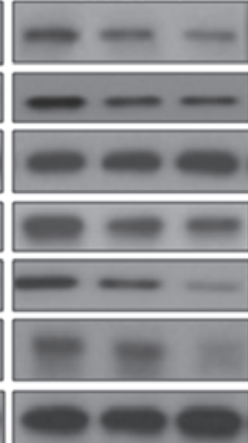

Con 160320
MDA-MB-231

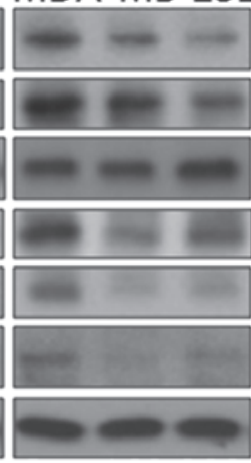

B

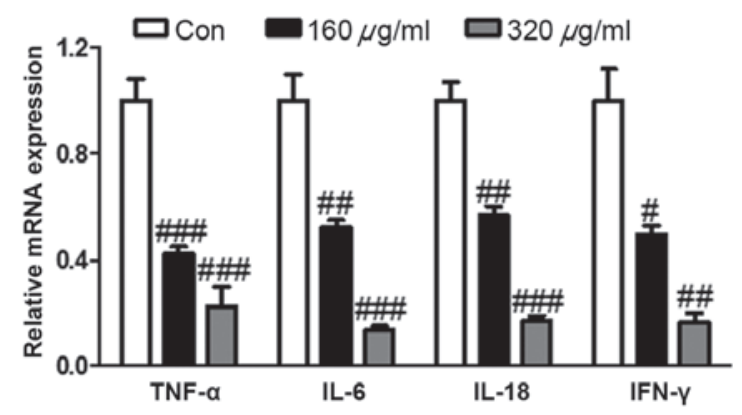

C
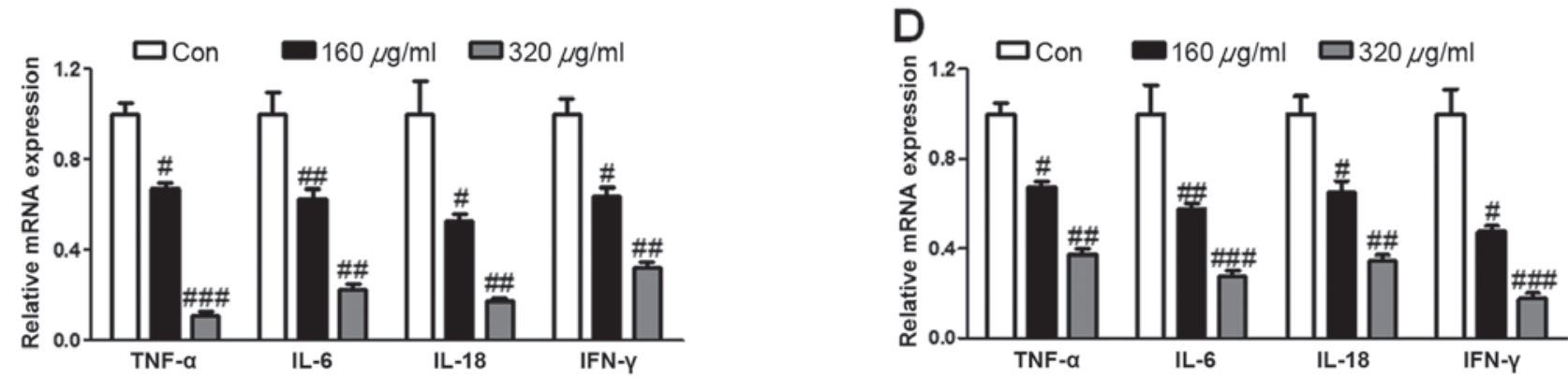

Figure 4. Ursolic acid suppresses inflammation response via the IKK $\alpha / \mathrm{NF}-\mathrm{kB}$ signaling pathway. (A) Western blot assays were used to determine levels of IKK $\alpha, \mathrm{I \kappa B} \alpha, \mathrm{p}-\mathrm{NF}-\kappa \mathrm{B}, \mathrm{IL}-1 \beta$ and IL-18 following treatment with 160 or $320 \mu \mathrm{g} / \mathrm{ml}$ ursolic acid. Inflammatory cytokines were determined via reverse transcription-quantitative polymerase chain reaction in (B) T47D, (C) MCF-7 and (D) MDA-MB-231 cell lines. Data are expressed as the mean \pm standard

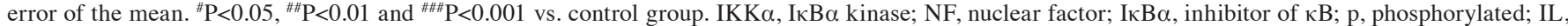
interleukin.

increase in AKT activity blocks the apoptotic pathway (34). PI3K activity contributes greatly to cellular transformations and the development of cancer (35). The PI3K/AKT signaling pathway is thus an important part of the intracellular signal transduction, cell proliferation, differentiation, apoptosis and migration (36) and the PI3K/AKT signaling pathway has previously been implicated in tumor growth and metastasis $(37,38)$. In the present study, it was demonstrated that ursolic acid reduced PI3K expression in the T47D, MCF-7 and MDA-MB-231 cell lines, consequently inactivating PI3K and downregulating AKT levels, which may attenuate breast cancer progression. GSK-3 $\beta$ is an essential downstream protein of AKT linked to the pathological process of tissue damage and the PI3K/AKT signal transduction pathway may affect the activity of GSK-3 $\beta$ (39). Activated AKT inhibits GSK-3 $\beta$ activity via phosphorylation (20). In accordance with previous studies, the results of the present study demonstrated that inactivated AKT upregulated GSK-3 $\beta$ expression in breast cancer cells following ursolic acid administration, indicating that ursolic acid may suppress breast cancer growth via the PI3K/AKT-regulated GSK signaling pathway. Furthermore, cyclin-D1, a downstream signal of GSK and an essential factor contributing to autophagy, was found to be downregulated in breast cancer cells following ursolic acid administration. Downregulation of cyclin-D1 inhibits cell proliferation via the induction of autophagy or cell death and may result in the prevention of breast cancer (40). LC3 is involved in autophagosome formation during autophagy (41). In the present study, LC3 mRNA levels were assessed in all three cell lines and were found to be upregulated by ursolic acid in a dose-dependent manner, indicating that autophagy occurs following ursolic acid administration.

Apoptosis is a regulated process that promotes the elimination of dysfunctional cells (42) and is regulated by pro- and anti-apoptotic members of the Bcl-2 protein family (43). It is accompanied by the activation of caspase-3, a member of the cysteine protease family, which includes caspase-9 (44). In the present study, the expression of Bcl-2 and Bcl-xL, another anti-apoptotic gene belonging to the Bcl-2 family, were significantly reduced following ursolic acid administration. Furthermore, Bad and Bax, both pro-apoptotic factors, were stimulated by ursolic acid and expression of caspase- 9 was significantly upregulated. Activated caspase- 9 enhances caspase-3 expression, which is crucial for the initiation of apoptosis (45). These results suggest that ursolic acid may suppress breast cancer by stimulating apoptosis in breast cancer cell lines.

It is well known that NF- $\kappa B$ serves a key role in inflammatory responses (46). Although the factors regulating NF- $\mathrm{\kappa B}$ transcriptional activity are not clearly understood, it is known that nuclear localization of redox sensitive NF- $\mathrm{KB}$ transcription factor is regulated by I $\kappa \mathrm{B} \alpha$ expression (47). In the present study, it was determined that ursolic acid suppressed the levels

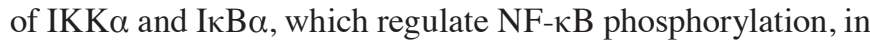
turn influencing the inflammatory response. Similarly, NF- $\kappa B$ activity was reduced following the inactivation of IкB $\alpha$, and IL-1 $\beta$ and IL-18 were significantly downregulated following ursolic acid treatment. Levels of other pro-inflammatory 
cytokines, including TNF- $\alpha$, IL-6, IL-18 and IFN- $\gamma$, were found to be suppressed, suggesting that ursolic acid is able to ameliorate breast cancer progression by inhibiting the inflammatory response in breast cancer cells.

In conclusion, the results of the present study demonstrate that ursolic acid treatment may inhibit the proliferation of breast cancer cells via inactivation of the PI3K/AKT signaling pathway. Ursolic acid administration was found to induce autophagy and apoptosis via the GSK and Bcl-2/Caspase-3 signaling pathways, and the inhibitory effect of ursolic acid on the inflammatory response was also involved in this mechanism. Therefore, these findings support the possibility of ursolic acid as a potential treatment for breast cancer.

\section{References}

1. Weigel MT and Dowsett M: Current and emerging biomarkers in breast cancer: Prognosis and prediction. Endocr Relat Cancer 17: R245-R262, 2010.

2. Ma X, Chen Z, Hua D, He D, Wang L, Zhang PJ, Cai Y, Gao C, Zhang $\mathrm{X}$, Zhang $\mathrm{F}$, et al: Essential role for TrpC5-containing extracellular vesicles in breast cancer with chemotherapeutic resistance. Proc Natl Acad Sci USA 111: 6389-6394, 2014.

3. Grau JJ,Zanon G, Caso C, Gonzalez X, Rodriguez A, Caballero M and Biete A: Prognosis in women with breast cancer and private extra insurance coverage. Ann Surg Oncol 20: 2822-2827, 2013.

4. Mereno-Aspitia A, Hillman DW, Dyar SH, Tenner KS, Gralow J, Kaufman PA, Davidson NE, Lafky JM, Reinholz MM, Lingle WL, et al: Soluble human epidermal growth factor receptor 2 (HER2) levels in patients with HER2-positive breast cacner receiving chemotherapy with or without trastuzumab: Results from North Central Cancer Treatment Group adjuvant trail N9831. Cancer 119: 2675-2682, 2013

5. Mouridsen HT and Robert NJ: The role of aromatase inhibitors as adjuvant therapy for early breast cancer in postmenopausal women. Eur J Cancer 41: 1678-1689, 2005.

6. Partridge AH, Rumble RB, Carey LA, Come SE, Davidson NE, Di Leo A, Gralow J, Hortobagyi GN, Moy B, Yee D, et al: Chemotherapy and targeted therapy for women with human epidermal growth factor receptor 2-negative (or unknown) advanced breast cancer: American society of clinical oncology clinical practice guideline. J Clin Oncol 32: 3307-3329, 2014.

7. Majewski IJ, Nuciforo P, Mittempergher L, Bosma AJ, Eidtmann H, Holmes E, Sotiriou C, Fumagalli D, Jimenez J, Aura C, et al: PIK3CA mutations are associated with decreased benefit to neoadjuvant human epidermal growth factor receptor 2-targeted therapies in breast cancer. J Clin Oncol 33: 1334-1339, 2015 .

8. Li-Weber M: New therapeutic aspects of flavones: The anti-cancer properties of Scutellaria and its main active constituents Wogonin, Baicalein and Baicalin. Cancer Treat Rev 35: $57-68,2009$.

9. Shishodia S, Majumdar S, Banerjee S and Aggarwaal BB: Ursolic acid inhibits nuclear factor-kappaB activation induced by carcinogenic agents through suppression of IkappaBalpha kinase and p65 phosphorylation: Correlation with down-regulation of cyclo-oxygenase 2 , matrix metalloproteinase 9, and cyclin D11. Cancer Res 63: 4375-4383, 2003.

10. Achiwa Y, Hasegawa K, Komiya T and Udagawa Y: Ursolic acid induces Bax-dependent apoptosis through the caspase-3 pathway in endometrial cancer SNG-II cells. Oncol Rep 13: 51-57, 2005.

11. Zheng Q, Jin F, Yao C, Zhang T, Zhang GH and Ai X: Ursolic acid-induced AMP-activated protein kinase (AMPK) activation contributes to growth inhibition and apoptosis in human bladder cancer T24 cells. Biochem Biophys Res Commun 419: 741-747, 2012.

12. Zheng QY, Li PP, Jin FS, Yao C, Zhang GH, Zang T and Ai X: Ursolic acid induces ER stress response to activate ASK1-JNK signaling and induce apoptosis in human bladder cancer T24 cells. Cell Signal 25: 206-213, 2013.

13. Li J, Liang X and Yang X: Ursolic acid inhibits growth and induces apoptosis in gemcitabine-resistant human pancreatic cancer via the JNK and PI3K/Akt/NF- $\kappa$ B pathways. Oncol Rep 28: 501-510, 2012.
14. Wu B, Wang X, Chi ZF, Hu R, Zhang R, Yang W and Liu ZG: Ursolic acid-induced apoptosis in K562 cells involving upregulation of PTEN gene expression and inactivation of the PI3K/Akt pathway. Arch Pharm Res 35: 543-548, 2012.

15. Kassi E, Papoutsi Z, Pratsinis H, Aligiannis N, Manoussakis M and Moutsatsou P: Ursolic acid, a naturally occurring triterpenoid, demonstrates anticancer activity on human prostate cancer cells. J Cancer Res Clin Oncol 133: 493-500, 2007.

16. Zhang Y, Kong C, Zeng Y, Wang L, Li Z, Wang H, Xu C and Sun Y: Ursolic acid induces PC-3 cell apoptosis via activation of JNK and inhibition of Akt pathways in vitro. Mol Carcinog 49: 374-385, 2010.

17. Shanmugam MK, Rajendran P, Li F, Nema T, Vali S, Abbasi T, Kapoor S, Sharma A, Kumar AP, Ho PC, et al: Ursolic acid inhibits multiple cell survival pathways leading to suppression of growth of prostate cancer xenograft in nude mice. J Mol Med (Berl) 89: 713-727, 2011.

18. Zhang B, Ji X, Zhang S, Ren H, Wang M, Guo C and Li Y: Hemin-mediated neuroglobin induction exerts neuroprotection following ischemic brain injury through PI3K/Akt signaling. Mol Med Rep 8: 681-685, 2013.

19. Prasad R, Vaid M and Katiyar SK: Grape proanthocyanidin inhibit pancreatic cancer cell growth in vitro and in vivo through induction of apoptosis and by targeting the PI3K/Akt pathway. PLoS One 7: e43064, 2012.

20. Wang Y, Feng W, Xue W, Tan Y, Hein DW, Li XK and Cai L: Inactivation of GSK-3beta by metallothionein prevents diabetes-related changes in cardiac energy metabolism, inflammation, nitrosative damage, and remodeling. Diabetes 58: 1391-1402, 2009.

21. Haddad JJ: The role of Bax/Bcl-2 and pro-caspase peptides in hypoxia/reperfusion-dependent regulation of MAPK (ERK): Discordant proteomic effect of MAPK(p38). Protein Pept Lett 14: 361-371, 2007

22. Paasch U, Grunewald S, Fitzl G and Glander HJ: Deterioration of plasma membrane is associated with activation of caspases in human spermatozoa. J Androl 24: 246-252, 2003.

23. Yu P, Liu Q, Liu K, Yagasaki K, Wu E and Zhang G: Matrine suppresses breast cancer cell proliferation and invasion via VEGF-Akt-NF-kappaB signaling. Cytotechnology 59: 219-229, 2009.

24. Keklikoglou I, Koerner C, Schmidt C, Zhang JD, Heckmann D, Shavinskaya A, Allgayer H, Gückel B, Fehm T, Schneeweiss A, et al: MicroRNA-520/373 family functions as a tumor suppressor in estrogen receptor negative breast cancer by targeting NF- $\mathrm{KB}$ and TGF- $\beta$ signaling pathways. Oncogene 31: 4150-4163, 2012.

25. Bower JE, Ganz PA, Irwin MR, Arevalo JM and Cole SW: Fatigue and gene expression in human leukocytes: Increased NF- $\mathrm{KB}$ and decreased glucocorticoid signaling in breast cancer survivors with persistent fatigue. Brain Behav Immun 25: 147-150, 2011.

26. Livak KJ and Schmittgen TD: Analysis of relative gene expression data using real-time quantitative PCR and the 2(-Delta Delta C(T)) method. Methods 25: 402-408, 2001

27. Kim DH, Ko IG, Kim BK, Kim TW, Kim SE, Shin MS, Kim CJ, Kim H, Kim KM and Baek SS: Treadmill exercise inhibits traumatic brain injury-induced hippocampal apoptosis. Physiol Behav 101: 660-665, 2010.

28. Kundu M and Thompson CB: Autophagy: Basic principles and relevance to disease. Annu Rev Pathol 3: 427-455, 2008.

29. Lu WJ, Lin KH, Hsu MJ, Chou DS, Hsiao G and Sheu JR: Suppression of $\mathrm{NF}-\kappa \mathrm{B}$ signaling by andrographolide with a novel mechanism in human platelets: Regulatory roles of the p38 MAPK-hydroxyl radical-ERK2 cascade. Biochem Pharmacol 84: 914-924, 2012.

30. Sánchez-Muñoz A, Ribelles N and Alba E: Optimal adjuvant hormonal therapy in postmenopausal women with hormone-receptor-positive early breast cancer: Have we answered the question? Clin Transl Oncol 12: 614-620, 2010.

31. Liobikas J, Majiene D, Trumbeckaite S, Kursvietiene K, Masteikova R, Kopustinkinene DM, Savickas A and Bernatoniene J: Uncoupling and antioxidant effects of ursolic acid in isolated rat heart mitochondria. J Nat Prod 74: 1640-1644, 2011.

32. Sun CH, Chang YH and Pan CC: Activation of the $\mathrm{PI} 3 \mathrm{~K} / \mathrm{Akt} / \mathrm{mTOR}$ pathway correlates with tumour progression and reduced survival in patients with urothelial carcinoma of the urinary bladder. Histopathology 58: 1054-1063, 2011.

33. Zhang J, Wang W, Lin Q, Zhang Q, Lai D and Qi C: Ursolic acid inhibits the proliferation of human ovarian cancer stem-like cells through epithelial-mesenchymal transition. Oncol Rep 34: 2375-2384, 2015. 
34. Shin DY, Kim GY, Lee JH, Choi BT, Yoo YH and Choi YH: Apoptosis induction of human prostate carcinoma DU145 cells by diallyl disulfide via modulation of JNK and PI3K/AKT signaling pathways. Int J Mol Sci 13: 14158-14171, 2012.

35. Fresno Vara JA, Casado E, de Castro J, Cejas P, Belda-Iniesta C and González-Barón M: PI3K/Akt signalling pathway and cancer. Cancer Treat Rev 30: 193-204, 2004.

36. Li Y, Jiang Y, Wan Y, Zhang L, Tang W, Ma J, Wu S and Cheng W: Medroxyprogestogen enhances apoptosis of SKOV-3 cells via inhibition of the PI3K/Akt signaling pathway. J Biomed Res 27: 43-50, 2013.

37. Dienstmann R, Rodon J, Serra V and Tabernero J: Picking the point of inhibition: A comparative review of PI3K/AKT/mTOR pathway inhibitors. Mol Cancer Ther 13: 1021-1031, 2014.

38. Leung E, Kim JE, Rewcastle GW, Finlay GJ and Baguley BC: Comparison of the effects of the PI $3 \mathrm{~K} / \mathrm{mTOR}$ inhibitors NVP-BEZ235 and GSK2126458 on tamoxifen-resistant breast cancer cells. Cancer Biol Ther 11: 938-946, 2011.

39. Bharti S, Golechha M, Kumari S, Siddiqui KM and Arya DS Akt/GSK-3//eNOS phosphorylation arbitrates safranal-induced myocardial protection against ischemia-reperfusion injury in rats. Eur J Nutr 51: 719-727, 2012.

40. Manderosian M, Sharma A, Funk AP, Vartanian R, Mastri J, Jo OD and Gera JF: Tristetraprolin regulates cyclin D1 and c-Myc mRNA stability in response to rapamycin in an Akt-dependant manner via p38 MAPK signaling. Oncogene 25: 6277-6290, 2006.
41. Tanida I, Ueno T and Kominami E: LC3 conjugation system in mammalian autophagy. Int J Biochem Cell Biol 36: 2503-2518, 2004.

42. Li Q, Zhang R, Guo YL and Mei YW: Effect of neuregulin on apoptosis and expressions of STAT3 and GFAP in rats following cerebral ischemic reperfusion. J Mol Neurosci 37: 67-73, 2009.

43. Hoshyar R, Bathaie SZ and Sadeghizadeh M: Crocin triggers the apoptosis through increasing the $\mathrm{Bax} / \mathrm{Bcl}-2$ ratio and caspase activation in human gastric adenocarcinoma, AGS, cells. DNA Cell Biol 32: 50-57, 2013.

44. Haddad JJ: The role of Bax/Bcl-2 and pro-caspase peptides in hypoxia/reperfusion-dependent regulation of $\mathrm{MAPK}(\mathrm{ERK})$ : Discordant proteomic effect of MAPK(p38). Protein Pept Lett 14: 361-371, 2007.

45. Floyd DH, Zhang Y, Dey BK, Kefas B, Breit H, Marks K, Dutta A, Herold-Mende C, Synowitz M, Glass R, et al: Novel anti-apoptotic microRNAs $582-5$ p and 363 promote human glioblastoma stem cell survival via direct inhibition of caspase 3 , caspase 9, and Bim. PLoS One 9: e96239, 2014.

46. Xiong HQ, Abbruzzese JL, Lin E, Wang L, Zheng L and Xie K: NF-kappaB activity blockade impairs the angiogenic potential of human pancreatic cancer cells. Int J Cancer 108: 181-188, 2004.

47. Maeda S, Yoshida H, Ogura K, Mitsuno Y, Hirata Y, Yamaji Y, Akanuma M, Shiratori Y and Omata M: H. Pylori activates NF-kappaB through a signaling pathway involving IkappaB kinases, NF-kappaB-inducing kinase, TRAF2, and TRAF6 in gastric cancer cells. Gastroenterology 119: 97-108, 2000. 